In This Issue:

\title{
Innovations in Primary Care and at the Annals
}

\author{
Michael E. Johansen, MD, MS, Associate Editor \\ Kurt C. Stange, MD, PbD, Editor \\ Ann Fam Med 2017;15:202-203. https://doi.org/10.1370/afm.2089.
}

$\mathrm{T}$ This issue features a wide range of innovations, research on the practice effects of policy changes around the world, and perspectives on mental health. We are also delighted to introduce two new Annals features: Innovations in Primary Care and Twitter Journal Club.

\section{INNOVATIONS}

We are pleased to introduce a new feature on Innovations in Primary Care. ${ }^{1-7}$ Articles in this new feature are brief-they fit on a single page, with additional detail in online appendixes and other links. Each article describes an innovation from the front lines of primary care, how it works, who implemented it and where it was carried out-information readers need to make decisions about how to transport or reinvent the innovation in their own setting. Articles close with takeaway lessons. We encourage readers to submit their own innovations for consideration, and to encourage innovators (who may not read this journal!) to submit their story and experience to this new feature. Submission information is available in the Call for Innovations and the revised Annals Instructions for Authors. We want to see novel approaches that make a difference on the ground in primary health care and in its partnerships with others improving health.

Several research articles in this issue evaluate innovations that are broader in scope: technological advances with potential to improve practice and patient outcomes.

Chronic dizziness can be challenging to treat in primary care. Geraghty and colleagues perform a pragmatic randomized controlled trial of a publicly available Internet-based vestibular rehabilitation intervention. ${ }^{8}$ They report decreased vertigo symptoms in the intervention arm. This article is featured in the Annals Journal Club. ${ }^{9}$ It will also launch a special Twitter journal club on May 31 from noon-1 Eastern Standard Time (4 pm Greenwich Mean Time) with the hashtag
\#AJC. This will be a moderated Twitter chat with questions about the article posed at regular intervals. We encourage learners at all stages to join us.

Technology also has the capacity to provide care in more efficient and convenient ways. Screening for cancer might be made more efficient with the use of a patient portal ${ }_{i}$ Krist and colleagues study this among 55,453 patients using a portal in 12 practices. They identify patients facing a potential cancer screening decision, enumerate participation rates, and find that many patient-reported aspects of decision making are improved. ${ }^{10}$

Telehealth video visits are another innovation that can shape and be shaped by the patient experience. In a qualitative study of patients having video visits, Rising et al find that patients value the convenience and lower cost of video visits, and some appreciate the comfort of being in their own environment. Patients also identify privacy concerns and note limitations in being physically examined. ${ }^{11}$

A novel hepatitis $C$ treatment program described by Lasser et al contains innovations in multiple areas including integrating primary care and public health, addressing social determinants of health, and revenue generation. ${ }^{12}$

\section{PRACTICE EFFECTS OF POLICY CHANGES}

In an environment of multiple practice reforms, Katz and colleagues evaluate the degree to which primary care across Canada comports with the goals of the Patient Medical Home model. In surveys of 772 primary care practices and 7,172 patients, they score practices as an average of 5 out of 10 in meeting Patient Medical Home model goals. ${ }^{13}$

In the United States, Eggleton and colleagues conduct a content analysis of a new value-based payment approach, the Merit-Based Incentive Payment System or MIPS. Their analysis raises concerns about the balance of MIPS measures and the consequences of 
limited measurement of access, patient experience, and interpersonal care. ${ }^{14}$

In China, a national policy on developing primary care through community health centers has succeeded in establishing a large number of centers. In a study with a sophisticated sampling strategy and a high response rate, Wong and colleagues find challenges in patient acceptance and in the comprehensiveness of care provided..$^{15}$

In dueling point / counterpoint articles, Hahn argues that quality measurement has made him a worse physician, ${ }^{16}$ while Scrase contends that quality measurement and reporting have the potential to improve patient outcomes. ${ }^{17}$

\section{MENTAL HEALTH}

Carr and colleagues study individuals with a history of self harm, and find a large increase in risk of premature death of both natural and unnatural causes. Based on these findings, the authors call for multidisciplinary preventive interventions in primary care. ${ }^{18}$

Examining the effectiveness of psychological or educational primary care interventions to prevent depression, a systematic review and meta-analysis of clinical trials finds a small effect. ${ }^{19}$

Finally, in contrast, or perhaps in complement to the high-tech interventions in this issue, an essay by Edgoose explores the possibilities for generating hope through a low-tech means: the face-to-face encounter. ${ }^{20}$

We welcome you to join the online discussion for each of the articles at http://www.AnnFamMed.org.

\section{References}

1. Frank $O$, Stocks $N$, Knieriemen A. Providing "just-in-time" preventive care advice. Ann Fam Med. 2017;15(3):276.

2. Blane DN, Sambale $P$, Williamson AE, Watt $G$. A change model for GPs serving deprived areas. Ann Fam Med. 2017;15(3):277.

3. Blair T, Lawson S, Porter H. Blood pressure screening in the dental office. Ann Fam Med. 2017;15(3):278.
4. Hodge B, Crane S. Engaging complex patients with drop-in group medical appointments. Ann Fam Med. 2017;15(3):279.

5. Frank RM, Carragino CL, Ferrante JM. Overcoming obesity one patient at a time. Ann Fam Med. 2017;15(3):280.

6. Jerzak J. Radical redesign: the power of team-based care. Ann Fam Med. 2017;15(3):281.

7. Hayes WC. Using QR codes to connect patients to health information Ann Fam Med. 2017;15(3):275.

8. Geraghty AWA, Essery R, Kirby $\mathrm{S}$, et al. Internet-based vestibular rehabilitation for older adults with chronic dizziness: a randomized controlled trial in primary care. Ann Fam Med. 2017;15(3):209-216.

9. Johansen ME, Stange KC. Annals Journal Club: Internet-based vestibular rehabilitation for chronic dizziness. Ann Fam Med. 2017;15(3):iii.

10. Krist $\mathrm{AH}$, Woolf $\mathrm{SH}$, Hochheimer $\mathrm{C}$, et al. Harnessing information technology to inform patients facing routine decisions: cancer screening as a test case. Ann Fam Med. 2017;15(3):217-224.

11. Powell RE, Henstenburg JM, Cooper G, Hollander JE, Rising KL. Patient perceptions of telehealth primary care video visits. Ann Fam Med. 2017;15(3):225-229.

12. Lasser $K E$, Heinz $A$, Battisti $L$, et al. A hepatitis $C$ treatment program based in a safety-net hospital patient-centered medical home. Ann Fam Med. 2017;15(3):258-261.

13. Katz A, Herpai N, Smith G, et al. Alignment of Canadian primary care with the patient medical home model: a QUALICO-PC study. Ann Fam Med. 2017;15(3):230-236.

14. Eggleton K, Liaw W, Bazemore A. Impact of gaps in merit-based incentive payment system measures on marginalized populations. Ann Fam Med. 2017;15(3):255-257.

15. Wong WCW, Jiang S, Ong JJ, et al. Bridging the gaps between patients and primary care in China: a nationwide representative survey. Ann Fam Med. 2017;15(3):237-245.

16. Hahn DL. Counterpoint: how quality reporting made me a worse doctor. Ann Fam Med. 2017;15(3):206-208.

17. Scrase DR. Point: how quality reporting made me a better doctor. Ann Fam Med. 2017;15(3):204-206.

18. Carr MJ, Ashcroft DM, Kontopantelis E, et al. Premature death among primary care patients with a history of self-harm. Ann Fam Med. 2017;15(3):246-254.

19. Conejo-Cerón S, Moreno-Peral P, Rodríguez-Morejón A, et al. Effectiveness of psychological and educational interventions to prevent depression in primary care: a systematic review and meta-analysis. Ann Fam Med. 2017;15(3):262-271.

20. Edgoose J, Edgoose J. Finding hope in the face-to-face. Ann Fam Med. 2017;15(3):272-274. 